\title{
Sympathetic activation in rats with L-NAME-induced hypertension
}

\section{V.C. Biancardi, \\ C.T. Bergamaschi, \\ O.U. Lopes and \\ R.R. Campos}

Disciplina de Fisiologia Cardiovascular e Respiratória, Departamento de Fisiologia, Escola Paulista de Medicina, Universidade Federal de São Paulo, São Paulo, SP, Brasil

\section{Correspondence}

R.R. Campos

Departamento de Fisiologia

Cardiovascular e Respiratória

EPM, UNIFESP

Rua Botucatu, 862

04023-060 São Paulo, SP

Brasil

Fax: +55-11-5573-7820

E-mail: campos@fcr.epm.br

Research supported by FAPESP and CNPq (PRONEX).

......................

Received November 24, 2005 Accepted December 18, 2006

\begin{abstract}
We evaluated the hemodynamic pattern and the contribution of the sympathetic nervous system in conscious and anesthetized $(1.4 \mathrm{~g} / \mathrm{kg}$ urethane, $i v$ ) Wistar rats with L-NAME-induced hypertension $(20 \mathrm{mg} /$ $\mathrm{kg}$ daily). The basal hemodynamic profile was similar for hypertensive animals, conscious $(\mathrm{N}=12)$ or anesthetized $(\mathrm{N}=12)$ treated with L-NAME for 2 or 7 days: increase of total peripheral resistance associated with a decrease of cardiac output (CO) compared to normotensive animals, conscious $(\mathrm{N}=14)$ or anesthetized $(\mathrm{N}=14)$. Sympathetic blockade with hexamethonium essentially caused a decrease in total peripheral resistance in hypertensive animals (conscious, 2 days: from (means \pm SEM) $2.47 \pm 0.08$ to $2.14 \pm 0.07$; conscious, 7 days: from $2.85 \pm 0.13$ to $2.07 \pm 0.33$; anesthetized, 2 days: from $3.00 \pm 0.09$ to $1.83 \pm 0.25$ and anesthetized, 7 days: from $3.56 \pm 0.11$ to $1.53 \pm 0.10$ $\mathrm{mmHg} \mathrm{mL}-1 \mathrm{~min}^{-1}$ ) with no change in $\mathrm{CO}$ in either group. However, in the normotensive group a fall in $\mathrm{CO}$ (conscious: from $125 \pm 4.5$ to 96 \pm 4 ; anesthetized: from $118 \pm 1.5$ to $104 \pm 5.5 \mathrm{~mL} / \mathrm{min}$ ) was observed. The responses after hexamethonium were more prominent in the hypertensive anesthetized group. However, no difference was observed between conscious and anesthetized normotensive rats in response to sympathetic blockade. The present study shows that the vasoconstriction in response to L-NAME was mediated by the sympathetic drive. The sympathetic tone plays an important role in the initiation and maintenance of hypertension.
\end{abstract}

\section{Introduction}

The importance of the sympathetic nervous system (SNS) during the evolution of arterial hypertension depends on the specific origin and phase of the hypertensive state. Although an increase in SNS activity has been reported in different models of hypertension, controversy remains regarding the importance of this mechanism in the generation and maintenance of hypertension $(1,2)$.
Key words

- L-NAME hypertension

- Sympathetic nervous system

- Nitric oxide synthase

blockade

- Total peripheral resistance
The controversy regarding the role of the SNS in the pathogenesis of hypertension may be related in part to methodological aspects such as type and/or phase of the experimental model of hypertension and the use of anesthetized animals. In rats, for example, acute or chronic nitric oxide (NO) synthase (NOS) inhibition by $\mathrm{N}^{\mathrm{G}}$-nitro-Larginine methyl ester (L-NAME) causes an increase in blood pressure $(3,4)$. However, the underlying mechanisms mediating hy- 
pertension are incompletely understood. This model has an interesting feature: apparently the sympathetic drive plays a more important role in the chronic than in the early phase of L-NAME hypertension (5-8).

Previous studies have provided compelling evidence that chronic L-NAME-induced hypertension is caused by widespread vasoconstriction associated with a decrease in cardiac output (CO) (9-12). Most of the studies were performed on anesthetized rats and an important question is whether these data can be extrapolated to the conscious state during the evolution of hypertension. In conscious rats, acute intravenous infusion of LNMMA causes a much smaller increase in blood pressure than in anesthetized rats (13). In addition, acute hypertension induced by L-NMMA in conscious humans was accompanied by a decrease in sympathetic nerve activity (14). In contrast, in rats, after one week of L-NAME treatment, the hypertension was completely reversed by acute sympathetic ganglionic blockade (15).

The purpose of the present study was to re-evaluate the hypothesis that sympathetic activation contributes to maintaining but not to initiating the vasoconstriction and hypertension induced by inhibition of NO synthesis. We evaluated the importance of the sympathetic drive in the hemodynamic responses (changes in peripheral resistance and $\mathrm{CO}$ in response to acute ganglionic blockade) of $\mathrm{L}$ NAME-treated rats in two different phases of the evolution of hypertension. Since anesthesia may be a limiting factor in the study, conscious and anesthetized rats were evaluated.

\section{Material and Methods}

Animals were provided by the Central Animal House of the Federal University of São Paulo, Escola Paulista de Medicina. The experiments were approved by the Animal Experimental Ethics Committee of the Federal University of São Paulo - Escola Pau- lista de Medicina (Process No. 1536/04).

To obtain L-NAME-induced hypertension (Sigma-Aldrich, St. Louis, MO, USA), male Wistar rats (230-280 g) were treated orally by gavage with L-NAME $(20 \mathrm{mg} / \mathrm{kg}$, daily) for 2 or 7 days. Normotensive rats were used as controls. Upon arrival, the rats were randomly assigned to one of these groups according to treatment, i.e., normotensive animals or animals with hypertension induced by L-NAME treatment for 2 or 7 days. The experiments were performed in a group of conscious rats and in a group of rats under anesthesia.

In the anesthetized group, rats were anesthetized $24 \mathrm{~h}$ before the experiment with ketamine and xylazine ( 40 and $20 \mathrm{mg} / \mathrm{kg}$, ip, respectively) and instrumented with femoral venous and arterial catheters for drug injection and arterial pressure recording, respectively. Catheters were externalized through the neck.

On the next day, arterial pressure and heart rate (HR) were recorded in awake, freely moving rats, and the animals were then gradually anesthetized with a maximum dose of $1.4 \mathrm{~g} / \mathrm{kg}$ urethane, $i v$, over a period of approximately $1 \mathrm{~h}$ to avoid any change in basal arterial pressure in response to anesthesia. The adequacy of the anesthetic was ascertained by the lack of a dodge reaction to hind paw pinching and by pupil diameter. Additional anesthesia (5\% of the initial dose) was administered when necessary.

The trachea was cannulated for spontaneous ventilation with oxygen-enriched air (with a gas mixture of $100 \% \mathrm{O}_{2}$ and room air), and pulsatile arterial pressure was recorded with a P23XL transducer (Statham Instruments Division, Gould Inc., Cleveland, OH, USA) connected to a Biopac system (MP 100 workstation for PC). Mean arterial pressure (MAP) and HR were obtained from the arterial pressure signal. Rectal temperature was maintained at $37 \pm 0.5^{\circ} \mathrm{C}$ by means of a servo-controlled electric blanket.

$\mathrm{CO}$ was estimated by thermodilution us- 
ing the Cardiomax III system (Columbus Instruments Inc., Columbus, OH, USA). This method is based on the principles of dilution and uses a known quantity of cold solution injected into the bloodstream to create a thermal deficit as a variant of the indicatordilution method. Thus, a bolus of $100 \mu \mathrm{L}$ saline was injected in the right atrium through a catheter inserted into the right jugular vein. The changes in temperature were sensed by a thermistor positioned in the aortic arch introduced through the right carotid artery. A curve showing the change in temperature over time was calculated by the Cardiomax III system and converted into a measurement of CO. Stroke volume (SV) was also calculated by the Cardiomax III system, dividing $\mathrm{CO}$ by $\mathrm{HR}$.

To determine the basal levels of the cardiovascular parameters, three to four individual measurements of $\mathrm{CO}$ were performed over a period of $5 \mathrm{~min}$ and the basal value is reported as the mean of these individual values. The SNS tone was evaluated by acute hexamethonium (Sigma-Aldrich) injection $(20 \mathrm{mg} / \mathrm{kg}$, iv) and the measurements of cardiovascular parameters were performed when arterial pressure had reached a stable level just after the ganglionic blockade. Additional doses of hexamethonium (5 to 10 $\mathrm{mg} / \mathrm{kg}, i v$ ) did not cause any further decrease in cardiovascular parameters in any group.

Total peripheral resistance (TPR) was calculated by dividing MAP by $\mathrm{CO}$ and is reported as $\mathrm{mmHg} \mathrm{mL} \mathrm{min}^{-1} \mathrm{~min}^{-1}$.

Conscious rats were instrumented on the day of the experiment in the same way as the anesthetized rats (except for the trachea), under $2 \%$ halothane anesthesia and the experiments were performed at least $4 \mathrm{~h}$ after the end of surgery, when the basal values of cardiovascular parameters were considered to be normal.

\section{Statistical analysis}

Data are reported as means \pm SEM. The significance of changes in MAP, CO, SV, TPR, and HR was determined within each group by the Student paired $t$-test. The cardiovascular responses to microinjection of hexamethonium in conscious and anesthetized rats were assessed by one-way analysis of variance followed by the Student-Newman-Keuls test. Differences were considered to be significant for a $\mathrm{P}$ value $<0.05$.

\section{Results}

\section{Hemodynamic pattern of L-NAME-treated rats}

Conscious rats. Rats treated with LNAME for 2 (L-NAME-2d, N = 6) and 7 (LNAME-7d, $N=6$ ) days had a significant increase in MAP $(171 \pm 3$ and $161 \pm 3$ $\mathrm{mmHg}$, respectively) compared to the control group $(109 \pm 2 \mathrm{mmHg})$.

The main characteristic of hypertensive rats was a progressive statistically significant increase in TPR $(2.47 \pm 0.08$ and $2.85 \pm$ $0.13 \mathrm{mmHg} \mathrm{mL}^{-1} \mathrm{~min}^{-1}$ for L-NAME-2d and $7 \mathrm{~d}$ days, respectively) compared to the normotensive group $\left(0.92 \pm 0.04 \mathrm{mmHg} \mathrm{mL}^{-1}\right.$ $\left.\min ^{-1}\right)$. On the other hand, there was a large and progressive statistically significant decrease in $\mathrm{CO}(71 \pm 2.5$ and $59 \pm 2 \mathrm{~mL} / \mathrm{min}$ for 2 and 7 days, respectively) compared to control $(125 \pm 4.5 \mathrm{~mL} / \mathrm{min})$. All values are presented in Table 1.

Urethane-anesthetized rats. The main characteristic of this group was a progressive statistically significant increase in MAP (L-NAME-2d: $153 \pm 0.7$ and L-NAME-7d: $166 \pm 1.4 \mathrm{mmHg} ; \mathrm{N}=6$ and 6 , respectively), compared to the normotensive control group $(116 \pm 0.9 \mathrm{mmHg})$, as shown in Table 2 . The increase in MAP was also mediated by a progressive and significant increase in TPR (L-NAME-2d: $3.00 \pm 0.09$ and L-NAME$7 \mathrm{~d}$ : $3.56 \pm 0.11 \mathrm{mmHg} \mathrm{mL} \mathrm{min}^{-1} \mathrm{~min}^{-1}$, with a large decrease in CO (L-NAME-2d: $55 \pm 1.7$ and L-NAME-7d: $50 \pm 1.7 \mathrm{~mL} / \mathrm{min}$ ) compared to control group (TPR: $1.00 \pm 0.02$ 
$\mathrm{mmHg} \mathrm{mL} \mathrm{min}^{-1}$ and $\mathrm{CO}: 118 \pm 1.5 \mathrm{~mL} /$ $\mathrm{min})$. $\mathrm{CO}$ decreased mainly due to SV reduction, as shown in Table 2. A significant decrease in HR was also observed only in the 2-day group, as shown in Table 2.

Comparison of conscious and anesthetized rats. The L-NAME- $2 \mathrm{~d}$ conscious group had a significantly higher basal $\mathrm{CO}(71 \pm 2.5$ $\mathrm{mL} / \mathrm{min})$ and MAP (171 $\pm 3 \mathrm{mmHg})$ compared to anesthetized rats (CO: $55 \pm 1.7 \mathrm{~mL} /$ min; MAP: $153 \pm 0.7 \mathrm{mmHg}$ ). On the other hand, an increase in TPR was observed in response to anesthesia (3.00 \pm 0.09 for conscious rats and $2.47 \pm 0.08 \mathrm{mmHg} \mathrm{mL}^{-1} \mathrm{~min}^{-1}$

Table 1. Basal hemodynamic pattern of conscious rats with hypertension induced by 2 days (2d) and 7 days (7d) of L-NAME treatment and of normotensive conscious animals.

\begin{tabular}{lccccc}
\hline $\begin{array}{l}\text { Conscious } \\
\text { rats }\end{array}$ & $\begin{array}{c}\mathrm{CO} \\
(\mathrm{mL} / \mathrm{min})\end{array}$ & $\begin{array}{c}\mathrm{TPR}(\mathrm{mmHg} \\
\left.\mathrm{mL}^{-1} \mathrm{~min}^{-1}\right)\end{array}$ & $\begin{array}{c}\mathrm{SV} \\
(\mu \mathrm{L})\end{array}$ & $\begin{array}{c}\mathrm{MAP} \\
(\mathrm{mmHg})\end{array}$ & $\begin{array}{c}\mathrm{HR} \\
(\mathrm{bpm})\end{array}$ \\
\hline $\begin{array}{c}\text { Control } \\
(\mathrm{N}=14)\end{array}$ & $125 \pm 4.5$ & $0.92 \pm 0.04$ & $316 \pm 12.5$ & $109 \pm 2$ & $396 \pm 14$ \\
$\begin{array}{c}\text { L-NAME-2d } \\
(\mathrm{N}=6)\end{array}$ & $71 \pm 2.5^{*}$ & $2.47 \pm 0.08^{*}$ & $216 \pm 5^{*}$ & $171 \pm 3^{*}$ & $343 \pm 8.5^{*}$ \\
$\begin{array}{c}\text { L-NAME-7d } \\
(\mathrm{N}=6)\end{array}$ & $59 \pm 2^{*}$ & $2.85 \pm 0.13^{*}$ & $174 \pm 7^{*}$ & $161 \pm 3^{*}$ & $339 \pm 11$ \\
\hline
\end{tabular}

Data are reported as means \pm SEM. The rats were treated with $20 \mathrm{mg} / \mathrm{kg}$ L-NAME daily. $\mathrm{CO}=$ cardiac output; TPR $=$ total peripheral resistance; $\mathrm{SV}=$ stroke volume; $\mathrm{MAP}=$ mean arterial pressure; $\mathrm{HR}=$ heart rate.

${ }^{*} \mathrm{P}<0.05$ compared to the normotensive group (Student $t$-test).

Table 2. Basal hemodynamic pattern of anesthetized rats with hypertension induced by 2 days ( $2 \mathrm{~d})$ and 7 days ( $7 \mathrm{~d}$ ) of L-NAME treatment and of normotensive anesthetized animals.

\begin{tabular}{lccccc}
\hline $\begin{array}{l}\text { Anesthetized } \\
\text { rats }\end{array}$ & $\begin{array}{c}\mathrm{CO} \\
(\mathrm{mL} / \mathrm{min})\end{array}$ & $\begin{array}{c}\mathrm{TPR}(\mathrm{mmHg} \\
\left.\mathrm{mL}^{-1} \mathrm{~min}^{-1}\right)\end{array}$ & $\begin{array}{c}\mathrm{SV} \\
(\mu \mathrm{L})\end{array}$ & $\begin{array}{c}\mathrm{MAP} \\
(\mathrm{mmHg})\end{array}$ & $\begin{array}{c}\mathrm{HR} \\
(\mathrm{bpm})\end{array}$ \\
\hline $\begin{array}{c}\text { Control } \\
(\mathrm{N}=14)\end{array}$ & $118 \pm 1.5$ & $1.00 \pm 0.02$ & $262 \pm 4.5$ & $116 \pm 0.9$ & $454 \pm 5.2$ \\
$\begin{array}{c}\text { L-NAME-2d } \\
(\mathrm{N}=6)\end{array}$ & $55 \pm 1.7^{*}$ & $3.00 \pm 0.09^{*}$ & $135 \pm 4.5^{*}$ & $153 \pm 0.7^{*}$ & $429 \pm 4.5^{*}$ \\
$\begin{array}{l}\text { L-NAME-7d } \\
(\mathrm{N}=6)\end{array}$ & $50 \pm 1.7^{*}$ & $3.56 \pm 0.11^{*}$ & $118 \pm 2.8^{*}$ & $166 \pm 1.4^{*}$ & $444 \pm 3.3$ \\
\hline
\end{tabular}

Data are reported as means \pm SEM. The rats received $20 \mathrm{mg} / \mathrm{kg}$ L-NAME daily. CO = cardiac output; TPR = total peripheral resistance; SV = stroke volume; MAP = mean arterial pressure; $\mathrm{HR}=$ heart rate.

${ }^{*} \mathrm{P}<0.05$ compared to the normotensive group (Student $t$-test). for anesthetized rats). The low value found for $\mathrm{CO}$ in anesthetized animals was possibly due to a decrease in SV $(135 \pm 4.5 \mu \mathrm{L})$.

However, in the L-NAME-7d group, the difference observed with anesthesia was less evident than in the L-NAME-2d group; only a significant increase in TPR was observed (anesthetized 7-day-treated group: $3.56 \pm$ 0.11; 2-day-treated conscious animals: 2.85 $\pm 0.13 \mathrm{mmHg} \mathrm{mL}^{-1} \mathrm{~min}^{-1}$ ).

The increase in MAP in conscious rats was maximum after 2 days of treatment. In contrast, anesthetized rats showed a progressive statistically significant increase in MAP between 2 and 7 days mediated by a progressive statistically significant increase in TPR. Although there was no change in MAP between 2 and 7 days in conscious rats, a significant decrease in $\mathrm{CO}$ associated with an increase in TPR was observed, as shown Table 1.

In normotensive rats, anesthesia did not change the values of MAP, CO or TPR; there was only a significant increase in the basal level of HR, as shown in Table 2.

\section{Hemodynamic responses to acute sympathetic system blockade}

Acute SNS blockade with hexamethonium produced a significant decrease in MAP in all groups.

In conscious hypertensive animals, the fall in MAP observed after hexamethonium was mediated only by a decrease in TPR; no changes in $\mathrm{CO}$ were observed in any group ( 2 and 7 days), as shown in Figure 1. The delta of the decrease in TPR after hexamethonium did not differ significantly between groups. However, the P value was close to the level of significance (2 days: $0.45 \pm 0.18$, and 7 days: $0.77 \pm 0.15 \mathrm{mmHg}$ $\left.\mathrm{mL}^{-1} \mathrm{~min}^{-1}, \mathrm{P}<0.1\right)$. Furthermore, the change in MAP in response to sympathetic blockade did not differ between the 2- and 7-day groups ( 2 days: $32.18 \pm 8.5$ and 7 days: $46.10 \pm 10 \mathrm{mmHg}$ ). 
In L-NAME-anesthetized hypertensive rats, the decrease in MAP after sympathetic blockade was more prominent 7 days (from $166 \pm 1.4$ to $78 \pm 7.9 \mathrm{mmHg}$ ) than 2 days after treatment (from $153 \pm 0.7$ to $88 \pm 6.2$ $\mathrm{mmHg}$; Figure 1). The fall in MAP was also mediated by a decrease in TPR in both groups. Different from what was observed in conscious rats, there was a significant difference between the 2- and 7-day groups regarding the TPR variation in response to the sympathetic blockade, with a larger decrease in the 7-day group ( 2 days: $1.17 \pm 0.18$ and 7 days: $2.02 \pm 0.28 \mathrm{mmHg} \mathrm{mL}^{-1} \mathrm{~min}^{-1}$ ).

Comparison of conscious and anesthetized animals showed that the fall in MAP after hexamethonium was greater in anesthetized animals. The larger fall in MAP in anesthetized rats was mediated by a decrease in TPR, both in the 2-day group and in the 7day group. The basal level of TPR was increased by anesthesia. In this case, the difference may have been related to the variation in the basal condition between groups. These data are shown in Figure 1.

In normotensive control rats there was no difference in the basal hemodynamic condition in response to anesthesia, as shown in Tables 1 and 2. The SNS blockade caused a decrease of MAP to acute spinal levels in both anesthetized and conscious rats (from $116 \pm 0.9$ to $62 \pm 1.8$ for anesthetized rats and from $109 \pm 2$ to $66 \pm 3 \mathrm{mmHg}$ for conscious rats), as shown in Figure 1. In addition, the change in MAP and TPR in response to hexamethonium was more marked in hypertensive than in normotensive rats.

The decrease of MAP in response to SNS blockade in the normotensive groups was due to a decrease in TPR and CO in conscious and in anesthetized rats, as shown in Figure 1. In this case, there was a differential hemodynamic response to sympathetic blockade by hypertensive and normotensive animals. In hypertensive rats, the sympathetic action was mainly on TPR, while in normotensive rats TPR and CO were affected.

\section{Discussion}

The new finding of the present study is that in conscious L-NAME-treated rats sympathetic activation appears in the initial phase of the development of hypertension. The sympathetic contribution to hypertension did not differ between 2 and 7 days of treatment. On the other hand, a time-dependent sympathetic activation in response to L-NAME

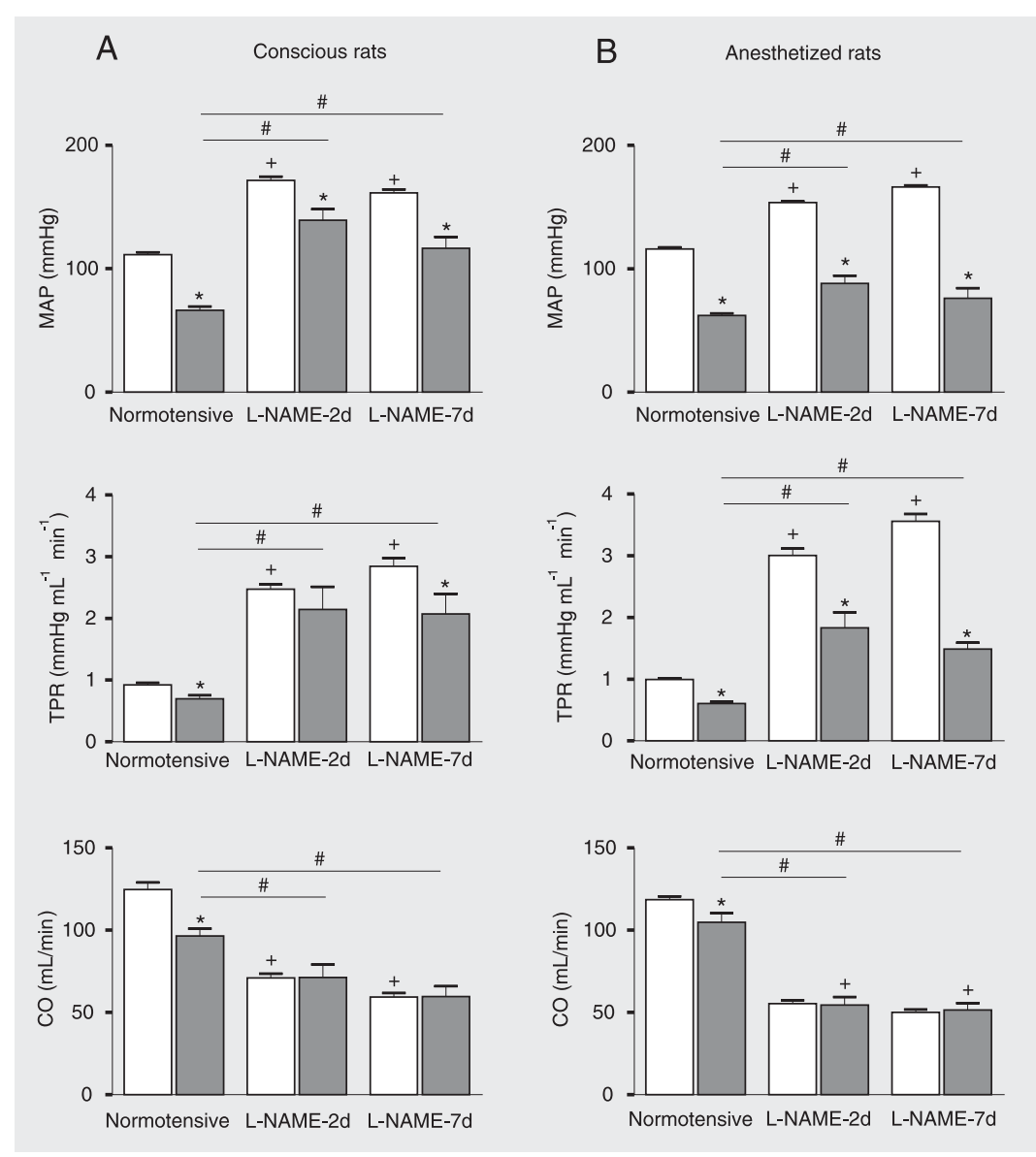

Figure 1. Mean arterial pressure (MAP), total peripheral resistance (TPR) and cardiac output (CO) before (open columns) and after (filled columns) administration of hexamethonium in the conscious $(A)$ and anesthetized $(B)$ condition for normotensive (normotensive, $\mathrm{N}=14$ and 6, respectively), L-NAME 2 days (L-NAME-2d, $\mathrm{N}=6$ and 6 , respectively) and LNAME 7 days (L-NAME-7d, $N=6$ and 6 , respectively) animals. ${ }^{*} P<0.05$ for the comparison of before and after hexamethonium injection, ${ }^{+} \mathrm{P}<0.05$ for the difference between normotensive and L-NAME groups before hexamethonium; $\mathrm{A}<0.05$ for the comparison of the normotensive and L-NAME groups after hexamethonium (one-way analysis of variance followed by the Student-Newman-Keuls test). 
was observed in anesthetized rats. Furthermore, in both conscious and anesthetized rats, the SNS plays a major role in the maintenance of L-NAME hypertension. Acute sympathetic blockade caused a decrease in $\mathrm{CO}$ and TPR in normotensive rats, while in hypertensive rats only a decrease in TPR was observed, indicating that hypertension is caused by a sympathetically mediated vasoconstriction.

Previous studies have provided evidence that chronic L-NAME-induced hypertension is not caused by an expanded plasma volume but rather by widespread vasoconstriction $(16,17)$. However, those studies were performed one week after NOS blockade and therefore they did not answer the question of whether the SNS plays an important role in mediating vasoconstriction and hypertension in the initial phase of NO inhibition.

Experiments in conscious instrumented animals provide a straightforward approach to this question. We found that in conscious rats the hemodynamic pattern in response to NO inhibition for 2 or 7 days was comparable. More importantly, the vasodilatation in response to sympathetic blockade was similar in the two phases studied. Thus, our results strongly suggest that L-NAME-induced hypertension is sympathetically mediated, even in the initial stage. We chose to study the contribution of the sympathetically mediated vasoconstriction in L-NAMEtreated animals 2 days after the beginning of treatment in order to avoid a baroreceptormediated compensatory action on sympathetic activity. It has been demonstrated that a chronically elevated level of arterial pressure will "reset" the set-point of the reflex to a higher operating point, such that some $48 \mathrm{~h}$ after the onset of elevation the reflex output will be back to its original level (18). In a previous study it was reported that acute NO blockade in baroreceptor-intact animals reduced sympathetic nerve activity. However, after barodenervation an increase in sympathetic nerve activity was observed (19). Taken together, these results suggest that in the initial phase the increase in the sympathetic nerve activity mediated by NO synthesis inhibition is compensated in part by baroreceptor activity.

The role of the SNS in L-NAME-induced hypertension is still controversial. Acute inhibition of the SNS in this model has been shown to produce either a substantial fall or a small change in blood pressure, particularly in the initial phase of hypertension. However, a progressive increase in sympathetic tone was reported by others ( 8 , 20,21). This discrepancy may be related to methodological reasons, such as the dose and duration of L-NAME treatment and the use of anesthesia. In the present study, we found that in conscious rats sympathetic activation is an important mechanism in the early stage of L-NAME hypertension; a timedependent sympathetic activation was observed only in anesthetized rats. The in vivo assessment of the role of the SNS in cardiovascular regulation is a challenging procedure. At the present time, there is no perfect method to quantify sympathetic activity, especially over long periods of time and particularly to compare different subjects. In the present study, we used acute hexamethonium bromide administration to measure hemodynamic variables. Our laboratory and others have used this technique to estimate the sympathetic support of arterial pressure $(8,22)$. Although this is a valid technique, it is only useful as an acute indicator of sympathetic involvement, and one limitation of this method is that it is not possible to differentiate the effects of sympathetic nerve activity blockade on different vascular beds. It has been shown before that chronic blockade of NO may increase the vascular response to sympathetic activation (23). However, it is not possible to discriminate between a possible increase in vascular reactivity to catecholamines and an increase in the central activation of the SNS with the ganglionic blockade. 
Furthermore, the mechanisms that lead to sympathetic activation during NO inhibition are not fully understood. There is a possibility that central NO mechanisms are involved in the control of sympathetic vasomotor activity. A number of studies have provided evidence that $\mathrm{NO}$ is involved in regulating sympathetic nervous activity within the brain. For example, intravenous injections of L-NAME increase arterial pressure and renal sympathetic nerve activity (19) and arterial pressure increased only when the SNS was intact (24). However, the exact mechanism of the increase in sympathetic drive mediated by L-NAME is still controversial. One possibility is that $\mathrm{NO}$ within the paraventricular nucleus (PVN) of the hypothalamus may serve as a physiological regulator of the SNS. PVN neurons project to several areas within the CNS involved in cardiovascular regulation, including the solitary tract nucleus, ventrolateral medulla and spinal cord. Perfusion of PVN neurons with NO-containing cerebrospinal fluid or microinjection of sodium nitroprusside into the PVN has been shown to elicit a significant reduction in arterial blood pressure (25). Furthermore, it has been proposed that decreased NO input and/or abnormalities in post-NO mechanisms within the PVN may contribute to the increase in sympathetic nerve activity commonly observed during disease states such as heart failure and hypertension (25).

There is a potential limitation of the present study that needs to be addressed. We used urethane as anesthesia, and it has been demonstrated that urethane increases the central drive to the adrenal medulla, leading to the secretion of epinephrine (26). However, when we compared the results of conscious and anesthetized rats, differences in the intensity of the responses to the sympathetic blockade were found only in L-NAMEtreated anesthetized rats compared to conscious L-NAME-treated rats, but not in normotensive anesthetized rats compared to normotensive conscious rats. Yet, an interaction between L-NAME treatment and the anesthetic cannot be excluded.

Recently, Augustyniak et al. (27) showed that acute infusion of L-NAME caused renal sympathetic activation in conscious animals when the confounding influence of the sinoaortic baroreceptors was eliminated after barodenervation. These data support the idea that acute L-NAME infusion induced sympathetic activation in conscious animals.

In the present study, the hypertension in response to NO blockade was associated with an increase in TPR and a decrease in CO. Recently, Charkoudian et al. (28) showed a similar hemodynamic pattern in humans in response to progressive NOS inhibition. They also showed that the hypertension in response to acute NO inhibition was significantly higher in individuals with high resting muscle sympathetic nerve activity (MSNA) compared to those with low resting MSNA. This result suggests that impairment of $\mathrm{NO}$ function can cause a greater risk of hypertension in individuals with higher MSNA compared to individuals with lower baseline MSNA.

Finally, the present study demonstrated that in conscious L-NAME-treated animals the increase in arterial pressure mediated by sympathetic vasoconstriction occurs from the initial phase to the maintenance phase of hypertension. However, a time-dependent sympathetic activation was more evident in anesthetized rats. 


\section{References}

1. Guyenet PG. The sympathetic control of blood pressure. Nat Rev Neurosci 2006; 7: 335-346.

2. Campos RR, Bergamaschi CT. Neurotransmission alterations in central cardiovascular control in experimental hypertension. Curr Hypertens Rev 2006; 2: 193-198.

3. Rees DD, Palmer RM, Schulz R, Hodson HF, Moncada S. Characterization of three inhibitors of endothelial nitric oxide synthase in vitro and in vivo. Br J Pharmacol 1990; 101: 746-752.

4. Ribeiro MO, Antunes E, De Nucci G, Lovisolo SM, Zatz R. Chronic inhibition of nitric oxide synthesis. A new model of arterial hypertension. Hypertension 1992; 20: 298-303.

5. Cunha RS, Cabral AM, Vasquez EC. Evidence that the autonomic nervous system plays a major role in the L-NAME-induced hypertension in conscious rats. Am J Hypertens 1993; 6: 806-809.

6. Zanzinger J, Czachurski J, Seller H. Impaired modulation of sympathetic excitability by nitric oxide after long-term administration of organic nitrates in pigs. Circulation 1998; 97: 2352-2358.

7. Sander M, Hansen J, Victor RG. The sympathetic nervous system is involved in the maintenance but not initiation of the hypertension induced by $\mathrm{N}$ (omega)-nitro-L-arginine methyl ester. Hypertension 1997; 30: 64-70.

8. Bergamaschi CT, Campos RR, Lopes OU. Rostral ventrolateral medulla: A source of sympathetic activation in rats subjected to long-term treatment with L-NAME. Hypertension 1999; 34: 744-747.

9. Rees DD, Palmer RM, Moncada S. Role of endothelium-derived nitric oxide in the regulation of blood pressure. Proc Natl Acad Sci U $S$ A 1989; 86: 3375-3378.

10. Sakuma I, Stuehr DJ, Gross SS, Nathan C, Levi R. Identification of arginine as a precursor of endothelium-derived relaxing factor. Proc Natl Acad Sci U S A 1988; 85: 8664-8667.

11. Whittle BJ, Lopez-Belmonte J, Rees DD. Modulation of the vasodepressor actions of acetylcholine, bradykinin, substance $\mathrm{P}$ and endothelin in the rat by a specific inhibitor of nitric oxide formation. $\mathrm{Br} \mathrm{J}$ Pharmacol 1989; 98: 646-652.

12. Ono $\mathrm{H}$, Ono $\mathrm{Y}$, Frohlich ED. Nitric oxide synthase inhibition in spontaneously hypertensive rats. Systemic, renal, and glomerular hemodynamics. Hypertension 1995; 26: 249-255.

13. Aisaka K, Mitani A, Kitajima $Y$, Ohno $T$, Ishihara $T$. Difference in pressor responses to NG-monomethyl-L-arginine between conscious and anesthetized rats. Jpn J Pharmacol 1991; 56: 245-248.

14. Hansen J, Jacobsen TN, Victor RG. Is nitric oxide involved in the tonic inhibition of central sympathetic outflow in humans? Hypertension 1994; 24: 439-444.

15. Sander M, Hansen PG, Victor RG. Sympathetically mediated hypertension caused by chronic inhibition of nitric oxide. Hypertension 1995; 26: 691-695.
16. Manning RD Jr, Hu L, Mizelle HL, Montani JP, Norton MW. Cardiovascular responses to long-term blockade of nitric oxide synthesis. Hypertension 1993; 22: 40-48.

17. Hu L, Manning RD Jr, Brands MW. Long-term cardiovascular role of nitric oxide in conscious rats. Hypertension 1994; 23: 185-194.

18. Chapleau MW, Li Z, Meyrelles SS, Ma X, Abboud FM. Mechanisms determining sensitivity of baroreceptor afferents in health and disease. Ann NY Acad Sci 2001; 940: 1-19.

19. Sakuma I, Togashi H, Yoshioka M, Saito H, Yanagida M, Tamura M, et al. NG-methyl-L-arginine, an inhibitor of L-arginine-derived nitric oxide synthesis, stimulates renal sympathetic nerve activity in vivo. A role for nitric oxide in the central regulation of sympathetic tone? Circ Res 1992; 70: 607-611.

20. Eshima K, Hirooka Y, Shigematsu H, Matsuo I, Koike G, Sakai K, et al. Angiotensin in the nucleus tractus solitarii contributes to neurogenic hypertension caused by chronic nitric oxide synthase inhibition. Hypertension 2000; 36: 259-263.

21. Thakali KM, Lau Y, Fink GD, Galligan JJ, Chen AF, Watts SW. Mechanisms of hypertension induced by nitric oxide (NO) deficiency: focus on venous function. J Cardiovasc Pharmacol 2006; 47: 742-750.

22. Collister JP, Osborn JW. The chronic infusion of hexamethonium and phenylephrine to effectively clamp sympathetic vasomotor tone. A novel approach. J Pharmacol Toxicol Methods 1999; 42: 135-147.

23. Nase GP, Boegehold MA. Nitric oxide modulates arteriolar responses to increased sympathetic nerve activity. Am J Physiol 1996; 271: H860-H869.

24. Ramchandra R, Barrett CJ, Malpas SC. Nitric oxide and sympathetic nerve activity in the control of blood pressure. Clin Exp Pharmacol Physiol 2005; 32: 440-446.

25. Horn T, Smith PM, McLaughlin BE, Bauce L, Marks GS, Pittman QJ, et al. Nitric oxide actions in paraventricular nucleus: cardiovascular and neurochemical implications. Am J Physiol 1994; 266: R306R313.

26. Armstrong JM, Lefevre-Borg F, Scatton B, Cavero I. Urethane inhibits cardiovascular responses mediated by the stimulation of alpha-2 adrenoceptors in the rat. J Pharmacol Exp Ther 1982; 223: 524-535.

27. Augustyniak RA, Victor RG, Morgan DA, Zhang W. L-NAME and ADMA-induced sympathetic neural activation in conscious rats. $A m$ J Physiol Regul Integr Comp Physiol 2006; 290: R726-R732.

28. Charkoudian N, Joyner MJ, Barnes SA, Johnson CP, Eisenach JH, Dietz NM, et al. Relationship between muscle sympathetic nerve activity and systemic hemodynamics during nitric oxide synthase inhibition in humans. Am J Physiol Heart Circ Physiol 2006; 291 : H1378-H1383. 